\title{
Irish university labs face external audits
}

\author{
Funding agency aims to affirm best practice with \\ independent checks on research methods.
}

\section{BY RICHARD VAN NOORDEN}

S cientists in Ireland will soon have to open up their lab notebooks and explain their research processes to outside auditors, according to plans outlined by the head of the country's basic-research funding agency.

Mark Ferguson, the director-general of Science Foundation Ireland (SFI), says that he has invited independent consultancy firms to bid for an unusual and unique annual auditing 质 exercise to start before the end of this year. The firms will check whether SFI-funded institutions, including all of Ireland's leading universities, have procedures in place for reporting

and investigating misconduct; whether management has followed those procedures in real cases; and whether any investigations have been carried out to a satisfactory standard.

For a small, random selection of SFI-funded grants, auditors will also check how experimental details have been recorded in lab notebooks and signed off by supervisors. In addition, they might ask to see the data behind particular papers.

"I don't want to cast us in the role of Big Brother. I want this to be constructive, polite and educative," Ferguson says. But he notes that checking that research is conducted with integrity is just as important as running routine financial audits. "It's to pick up mistakes and promulgate best practice. We are all in the business of making sure we are getting the best research for our money," he adds.

The plans follow the release on 4 June of the National Policy Statement on Ensuring Research Integrity in Ireland (go.nature.com/ lxvreq), which outlines common standards for Irish research. It was signed by major research institutions and funders, and is closely modelled on similar European and British agreements.

But whereas funders in other nations ask research organizations to assure them only that they are following the rules - and in some cases to report data on matters such as misconduct investigations - Ferguson says that annual external audits are needed to check compliance and to maintain public trust that money is well spent. "We have the right to withdraw a grant if there is serious mishandling," he says, although he does not expect to see anything beyond minor issues.

But some researchers question whether the audits are worthwhile. "This is an interesting idea but I am not sure it will really work. It may serve the profile of funders to say superficially that 'We have done our job well', but I doubt that the sample of audited work will be large enough and in depth enough to make any material difference," says John Ioannidis, a physician who studies research methodology at Stanford University in California. "It may add only another layer of bureaucratic

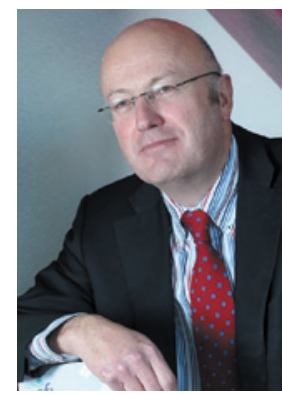
checks."

The US National Institutes of Health in Bethesda, Maryland, a major funder of biomedical research, takes a similar view. Although it has rules that organizations must abide by, it is not considering external audits, says Sally "I don't want to cast us in the role of Big Brother. I want this to be constructive, polite and educative." Mark Ferguson

Rockey, the deputy director for extramural research at the agency. Instead, it is focusing on enhancing researcher training to improve the reproducibility of research.
Ferguson admits that exhaustive audits would not be cost-effective for the SFI, an agency that gives out only around $€ 150$ million (US\$203 million) a year in grants. Auditors will not have a deep scientific knowledge or be expected to reinvestigate misconduct cases, so the auditing will be "fairly procedural", he says. The SFI would publish the broad findings of its audits, but not the fine details, which would be shared only with universities. "I don't want to stigmatize particular grant holders," Ferguson says.

Beyond early discussions, he has not talked through the plans in detail with research institutions. Nature's news team asked four universities for comment; they directed a reply through the Irish Universities Association. "We look forward to further discussing with SFI how the practical implementation of the policy may be best effected," a spokesperson said. 